\title{
Translocation of algal pigments to oocytes in Capitella sp. I (Annelida: Polychaeta)
}

\author{
A. G. Marsh*, A. Grémare**, R. Dawson, K. R. Tenore \\ Chesapeake Biological Laboratory, University of Maryland, Solomons, Maryland 20688, USA
}

\begin{abstract}
Juvenile Capitella sp. I were raised on 3 diets: a processed mixed cereal; benthic diatoms; and a green macroalgae. Accessory pigments from algal diets were translocated to developing oocytes. Worms fed mixed cereal produced eggs with no pigments; worms fed diatoms produced eggs with fucoxanthin, diadinoxanthin, diatoxanthin and $\beta$ carotene; worms fed macroalgae produced eggs with lutein, lutein cis-isomers and $\beta$-carotene. In addition to accessory pigments, chlorophylls and their breakdown products (pheaophytin and phaephorbide) and $\beta$-carotene anabolic products (canthaxanthin and echinenone) were also translocated to oocytes. The presence of intact chlorophyll a in eggs is evidence that Capitella sp. I can rapidly assimilate and allocate materials to reproduction. Given the importance of carotenoids in aquaculture diets, differences in oocyte carotenoid compositions may significantly alter growth and development rates of eggs produced on different food resources in field populations. In future studies, it may be possible to identify the food resources of opportunistic deposit-feeders from the biochemical composition (fatty acids, sterols, and pigments) of their oocytes.
\end{abstract}

In temperate estuaries, opportunistic deposit feeders generally exhibit high fecundities, rapid oogenesis, and continuous reproduction, producing large seasonal fluctuations in a population's reproductive output (Grémare et al. 1989). Seasonal variations in reproduction have been attributed to changes in food availability (Levin 1986, Zajac 1986), especially when phytodetritus sedimentation increases after phytoplankton blooms (Davies \& Payne 1984, Christensen \& Kenneworff 1985). Because phytoplankton blooms are seasonally ephemeral, a population of opportunists must immediately allocate assimilated food to reproduction with little time to catabolize those resources. Thus, in opportunists with high yolk requirements, nutrition of

- Present address: Dept. Zoology, Spaulding Life Sciences, University of New Hampshire, Durham, New Hampshire 03824, USA

- Present address: Laboratoire Arago, F-66 650 Banyuls sur Mer, France developing gametes is a problem when yolk-precursors must be translocated rapidly to as many oocytes as a body coelom can accommodate in the shortest amount of time as necessary for adequate yolk formation (Ecklebarger 1986).

The opportunistic polychaete Capitella sp. I has been shown to translocate fatty acids and sterols directly from its diet to developing oocytes (Marsh et al. 1990). In addition, Marsh et al. (1990) reported a large phytol peak (the C 29 isoprenoid side-chain of chlorophyll) in Capitella sp. I eggs produced by females raised on algal diets. The presence of phytol in these eggs suggests that algal pigments or their breakdown products could be translocated to developing oocytes. In crustaceans, dietary carotenoids may function as growth hormones, lipoprotein crosslinks to control membrane permeability, free-radical scavengers, antiphotooxidants and UV light absorbers (Castillo 1981). Thus, the presence of carotenoids in Capitella sp. I oocytes is not a trivial observation. At the very least, carotenoids could potentially serve as chemical markers for identifying the temporal food resources of deposit feeders. This study compares the pigment profiles of eggs produced by Capitella sp. I fed either a mixture of diatoms (Nitzschia and Navicula spp.) or a macroalgae (Ulva sp.).

Materials and methods. Stock cultures of Capitella sp. I, started from individuals collected at Woods Hole, Massachusetts (USA), were maintained at $20^{\circ} \mathrm{C}$ and $25 \%$ \% (Chesney \& Tenore 1985). Fecundity experiments were carried out by Grémare et al. (1988) to examine the effect of diet on egg production in Capitella sp. I. Immature juveniles ( $80 \mu \mathrm{g}$ dry wt) were sorted from stock cultures and placed in replicate finger bowls with different rations of either: (1) Gerber's Pablam, a mixed-grain cereal commercially available for babies (Gerber), (2) benthic diatoms, a mixture 
a freeze-dried Nitzschia sp, and Navicula sp. (diatoms), or (3) Ulva sp., a green macroalgae collected from Chesapeake Bay and freeze-dried (UIva). The levels of carbon, nitrogen, fatty acids, and amino acids in these foods is described elsewhere (Marsh et al. 1989). After $15 \mathrm{~d}$ mature eggs were dissected from gravid females and frozen in groups of 1000 to 2000 .

Eggs were ultrasonicated in $100 \%$ acetone at $4{ }^{\circ} \mathrm{C}$ after thawing. Samples were centrifuged $(10000 \times \mathrm{g})$ and the supernatants used for pigment analyses by ion pairing, reversed-phase HPLC after Bianchi et al. (1988). A programmable pump (Constametric III, LDC Milton-Roy with MP 3000 controller) established a gradient from $100 \%$ solvent A $(80: 10: 10$, methanol: water: $5.5 \%$ tetrabutyl ammonium acetate) to $100 \%$ solvent $B(70: 30$, methanol to acetone) in $30 \mathrm{~s}$ with a hold for $20 \mathrm{~s}$. Dual channel detection was achieved with an LDC UV monitor with $440 \mathrm{~nm}$ filter kit for absorbance and a Perkin-Elmer 650-10s fluoresence detector, excitation $440 \mathrm{~nm}$ and emission $670 \mathrm{~nm}$. Pigments were separated on an $250 \times 4 \mathrm{~mm} \mathrm{C18}, 5 \mu \mathrm{m}$ Adsorbosphere column. Standard chlorophyll and degradation products were prepared after Mantoura \& Llewellyn (1983). Pigments were identified by diode array spectroscopy (Waters model 990) and comparisons of retention times to isolated standards. The instruments at the Chesapeake Biological Laboratory have been calibrated with standards and reference algal cultures made available through the Joint Global Ocean Flux Studies-Plant pigment intercalibration program (Drs Bidigare and Kennicutt, Texas A \& M University, Austin).

Results. The pigment profiles of the experimental diets differed in both their quantities of chlorophyll a and their complement of accessory pigments. Gerber, a commercially bleached, grain-cereal extract, had no pigments present. The diatom accessory pigments were dominated by chlorophyll $c$, fucoxanthin, diadinoxanthin, and diatoxanthin (Fig. 1A). A trace of $\beta$ carotene was detected as well as an unknown pigment eluting just after diatoxanthin. The Ulva sp. accessory pigments were dominated by fucoxanthin, neoxanthin, lutein, and chlorophyll-b (Fig. 1B). Traces of $\beta$-carotene, violaxanthin, antheraxanthin, and lutein cis-isomers were detected.

Capitella sp. I females fed Nitzschia sp. and Navicula sp. produced eggs with diatom accessory pigments (Fig. 2A). Fucoxanthin, diadinoxanthin, diatoxanthin, canthaxanthin, echinenone and $\beta$-carotene were translocated to developing oocytes. Intact chlorophyll $a$ and its breakdown products (phaeophorbides and phytol) were also present in the eggs. The mixture of pheaophorbides probably included chlorophyll a and $c$ derivatives, however, the flourescence detector was
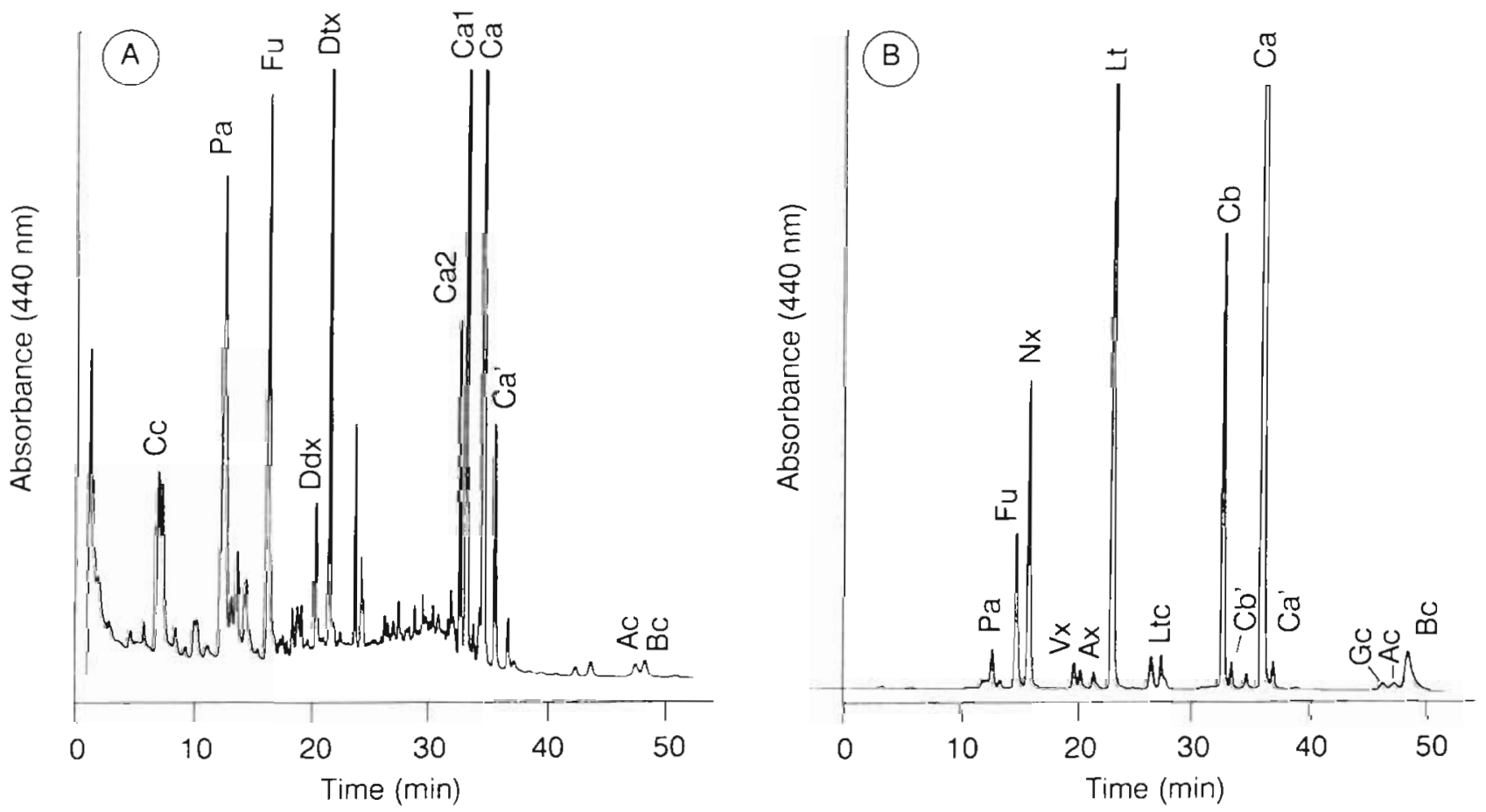

Fig. 1. Pigment profiles of the algal diets: (A) benthic diatoms, Nitzschia sp. and Navicula sp.; (B) the green macroalgae Ulva sp. Relative absorbance at $440 \mathrm{~nm}$ is followed during HPLC pigment separation. $\mathrm{An}=$ antheraxanthin; $\mathrm{Ac}=\alpha-\mathrm{carotene} ; \mathrm{BC}=\beta$ carotene; $\mathrm{Ca}=$ chlorophyll $a_{i} \mathrm{CA}^{\prime}=$ chlorophyll $a^{\prime} ; \mathrm{Ca} 1=$ chlorophyll $a$ allomer $1 ; \mathrm{Ca} 2=$ chlorophyll $a$ allomer $2 ; \mathrm{Cb}=$ chlorophyll $b ; \mathrm{Cb}^{\prime}=$ chlorophyll $b^{\prime} ; \mathrm{Cc}=$ chlorophyll $c ; \mathrm{Ddx}=$ diadinoxanthin; $\mathrm{Ddt}=$ diatoxanthin; Fu $=$ fucoxanthin; Gc $=\gamma-$ carotene; $\mathrm{Lt}=$ lutein; $\mathrm{Ltc}=$ lutein cis-isomers: $\mathrm{Nx}=9^{\prime}$-cis-neoxanthin; $\mathrm{Pa}=$ phaeophorbide $\mathrm{a} ; \mathrm{Vx}=$ violoxanthin 

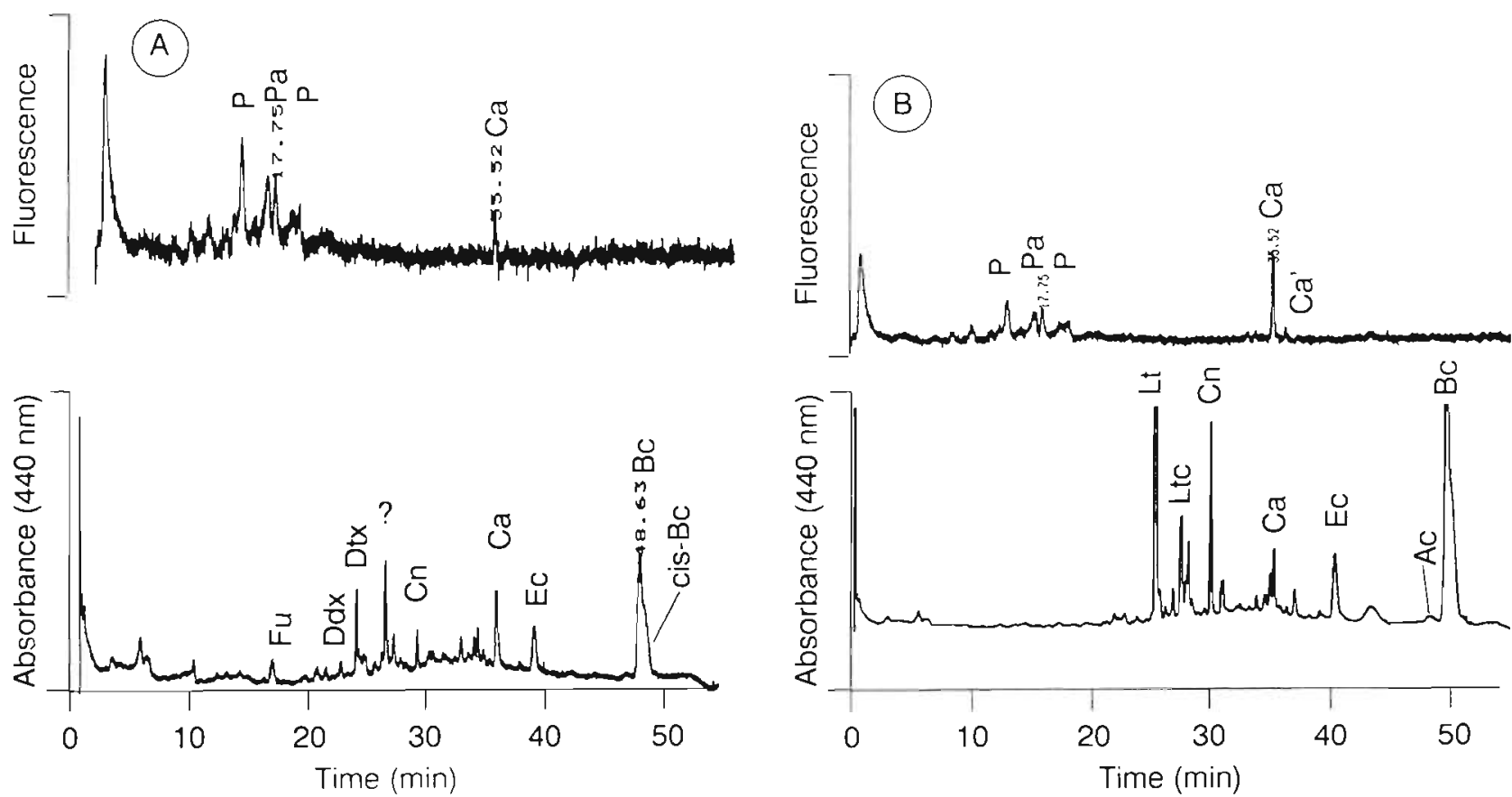

Fig. 2. Capitella sp. I. Pigment profiles of oocytes produced on the algal diets: (A) diatorns, (B) Ulva sp. Both relative absorbance and relative fluoresence are followed during HPLC pigment separation. $\mathrm{BC}=\beta$-carotene; $\mathrm{Ca}=$ chlorophyll $a_{;} \mathrm{Ca}^{\prime}=\mathrm{chlorophyll}$ $a^{\prime}: \mathrm{Cn}=$ canthaxanthin; $\mathrm{Ddx}=$ diadinoxanthin $; \mathrm{Ddt}=$ diatoxanthin $; \mathrm{EC}=$ echinenone $; \mathrm{Fu}=$ fucoxanthin; Lt $=$ lutein; Ltc $=$ lutein cis-isomers; $\mathrm{P}=$ phaeophorbide-like compounds, probably derivatives of chlorophylls $b$ and $c ; \mathrm{Pa}=$ phaeophorbide $\mathrm{a}_{;}$? $=$ unknown pigment translocated from diatom diet to oocytes

operating below its optimal response level and the identification of phaeophorbide $c$ is tenuous. Capitella sp. I females fed Ulva sp. produced eggs with green algal accessory pigments (Fig. 2B). Lutein, lutein cisisomers, canthaxanthin, echinenone, and $\beta$-carotene were translocated to developing oocytes. Again intact chlorophyll a and phaeophorbide products (possibly including derivatives of chlorophyll $b$ ) were also present and in such large quantities that these eggs had a visible yellow-green tint. Capitella sp. I females fed Gerber produced eggs with no pigments present.

Phaeophytins were not detected in the oocytes and supports the suggestion that Capitella sp. I can remove the phytol side chain of parent chlorophylls (Marsh et al. 1990). The presence of phaeophorbide and phytol in Capitella sp. I eggs indicates that during digestion, assimilation, and translocation, chlorophylls are degraded by removal of the magnesium ion and phytol side chain from the tetrapyrrole ring to form phaeophorbides. The degree of chlorophyll degradation is probably dependent on the rate at which digestion, assimilation and translocation proceed; the presence of intact chlorophyll molecules in the eggs indicates that these processes can occur rapidly in Capitella sp. I.

Discussion. Oogenesis in Capitella species is unique among polychaetes. The dorsal blood vessel passes between the ovaries in each segment, allowing follicle cells to immediately assimilate macromolecules from the circulatory system by endocytosis (Ecklebarger \& Grassle 1982). This characteristic provides Capitella species with the ability to translocate rapidly materials to developing oocytes. As a consequence, an adult female has little opportunity to metabolize or structurally rearrange materials assimilated from the gut before they are sequestered in oocytes. This may be true for other opportunists that have high fecundities, rapid oogenesis, and continuous breeding when resources are available. Capitella sp. I eggs produced by adults fed different diets can be discriminated in a principal component analysis of egg fatty acid and sterol composition (Marsh et al. 1990). The ability of Capitella sp. I to translocate chlorophyll a intact is evidence of the fast rates at which materials can be moved to oocytes.

Carotenoids appear to have a variety of physiological functions and their importance in aquaculture feeds has been well established (Simpson et al. 1981). Work on crustacean development with canthaxanthin (a $\beta$-carotene derivative) has shown that sequestering this carotenoid in oocytes provides a vitamin-A-like compound during development that is analogous to crustacean juvenile growth hormone (Ahl 1989). Work on fish has shown that echinenone (another $\beta$-carotene deriva- 
tive) can be converted to a provitamin A metabolite that increases bacterial and fungal disease resistance (Tacon 1981). These vitamin-A-like compounds have pronounced effects on reproductive physiology and can increase gonadal development, egg maturation and viability, and larval growth and survival (Tveranger 1986).

In polychaetes, $\beta$-carotene, canthaxanthin and echinenone are common tissue constituents (Dales 1962). $\beta$-carotene is obtained in the diet and converted to its derivatives. The influence of these carotenoids on growth, reproduction and development in field populations of opportunists is unknown. Given the importance of phytodetrital sedimentation in determining opportunistic population dynamics, carotenoids may be an important dietary micronutrient, such as essential fatty and amino acids, vitamins and cofactors. Although some dietary carotenoids may not be 'essential' for survival, their presence could potentially enhance reproductive and developmental rates, and thus significantly influence the potential for rapid population increases.

A secondary importance of dietary pigments in the eggs of deposit feeders lies in the potential for identifying their food resources. Capitella sp. I fed Ulva sp. transmits a green-algal signal to its oocytes, namely lutein and probably phaeophorbide $b$ compounds (at present only tentatively identified). Capitella sp. I fed Nitzschia sp. and Navicula sp. transmits a diatom sig nal to its oocytes, namely fucoxanthin, diadinoxanthin, diatoxanthin and probably phaeophorbide $C$ compounds. We speculate that Capitella sp. I fed dinoflagellates would produce eggs with the pigment peridinin and the sterol dinosterol; Capitella sp. I fed cryptomonads would produce eggs with alloxanthin. All of these pigments are unmistakable markers of feeding history. Fatty acid and sterol composition of oocytes in Capitella sp. I have been used to identify experimental diets on which females were raised. Carotenoid composition in conjunction with fatty acid and sterol profiles of oocytes may collectively provide a sensitive discriminant function to identify the food resources of opportunistic deposit-feeders in the field.

Acknowledgement. This research was supported by NSF Grant OCE-85-16-715 to K.R.T

\section{LITERATURE CITED}

Ahl, J. (1989). Juvenile hormone-like activity of the carotenoid canthaxanthin from Artemia. Am. Zool. 29: 111A

This note was submitted to the editor
Bianchi, T., Dawson, R., Sawangwong, P. (1988). The effects of macrobenthic deposit-feeding on the degradation of chloropigments in sandy sediments. J. exp. Mar. Biol. Ecol. 122: $243-255$

Castillo, R. (1981). General survey of the carotenoids in crustacea. In: Britton, A., Goodwin, R. (eds.) Carotenoid chemistry and biochemistry. Pergamon Press, Oxford, $p$ $64-81$

Chesney, E., Tenore, K. (1985). Oscillations of laboratory populations of the opportunistic polychaete Capitella capitata (Type I): their cause and implications for natural populations. Mar. Ecol. Prog. Ser. 20: 289-296

Christensen, H., Kanneworff, E. (1985). Sedimenting phytoplankton as major food source for suspension and deposit feeders in the Oresund. Ophelia 24: 223-224

Dales, R. (1962). Carotene pigments in the tissues of some common polychaetes from the British Isles. J. mar biol. Ass. U.K. 42: 259-274

Davies, J., Payne, R. (1984). Supply of organic matter to the sediment in the northern North Sea during a spring phytoplankton bloom. Mar. Biol. 78: 315-324

Ecklebarger, K. (1986). Vitellogenic mechanisms and the allocation of energy to offspring in polychaetes. Bull. mar. Sci. 39: $426-443$

Ecklebarger, K., Grassle, J. (1982). Ultrastructure of the ovary and oogenesis in the polychaeta Capitella jonesi (Hartman, 1959). J. Morph. 171: 305-320

Grémare, A., Marsh, A., Tenore, K. (1988). Short-term reproductive responses of Capitella sp. I (Annelida:Polychaeta) fed on different diets. J. exp. mar. Biol. Ecol. 123: 147-162

Grémare, A., Marsh, A., Tenore, K. (1989). Fecundity and energy partitioning in Capitella capitata (Type I) (Annelida:Polychaeta). Mar. Biol. 100: 365-371

Levin, L. (1986). Effects of enrichment on reproduction in the opportunistic polychaeta Streblospio benedicti (Webster): a mesocosm study. Biol. Bull. mar. biol. Lab., Woods Hole $171 \quad 143-160$

Mantoura, R., Llewellyn, C. (1983). The rapid determination of algal chlorophyll and carotenoid pigments and their breakdown products in natural waters by reverse-phase high-performance liquid chromatography. Analytica chim. Acta 151: 297-314

Marsh, A., Harvey, H., Grémare, A., Tenore, K. (1990). Dietary effects on oocyte yolk-composition in Capitella sp. I (Annelida: Polychaeta): fatty acids and sterols. Mar Biol. 106: $369-374$

Simpson, K., Katayama, T., Chichester, C. (1981). Carotenoids in fish feeds. In: Bauernfeind, J. (ed.) Carotenoids as colorants and vitamin precursors. Academic Press, London, p. $35-49$

Tacon, A. (1981). Speculative review of possible carotenoid function in fish. Progve Fish Cult 43: 205-208

Tveranger, B. (1986). Effect of pigment content in broodstock diet on subsequent fertilization rate, survival and growth rate of rainbow trout (Salmo gairdneri) offspring. Aquaculture 53: 85-93

Zajac, R. (1986). The effects of intra-specific density and food supply on growth and reproduction in an infaunal polychaete, Polydora ligni Webster. J. mar. Res. 44: 339-359

Manuscript received: June 20, 1990

Accepted: July 31, 1990 